\title{
OS LEILÕES SOB A ÓTICA DA ECONOMIA INSTITUCIONAL: EVIDÊNCIAS NO MERCADO BOVINO
}

\section{GESTÃO} $\&$ PRODUÇÃo

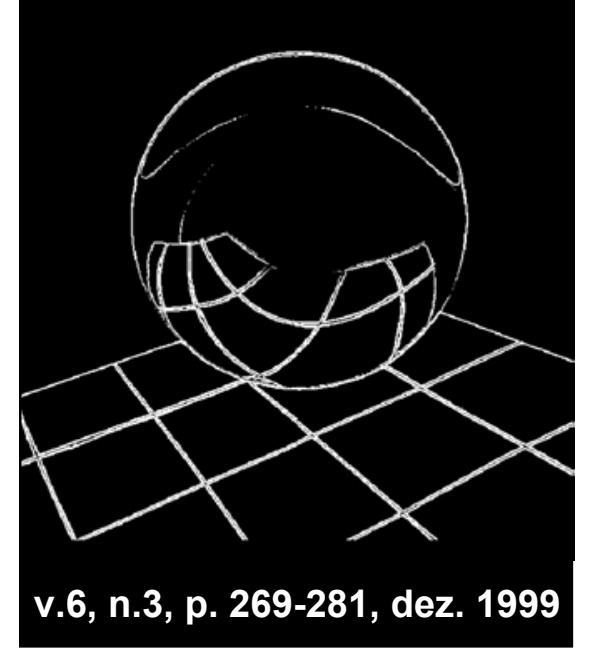

\author{
Cláudio Antonio Pinheiro Machado Filho \\ Departamento de Administração da FEA/USP \\ Pesquisador do PENSA \\ E-mail: capfilho@usp.br \\ Decio Zylbersztajn \\ Departamento de Administração da FEA/USP \\ Coordenador geral do PENSA \\ E-mail: dzilbers@usp.br
}

\section{Resumo}

Este trabalho discute o papel dos leilões a partir do referencial teórico da Nova Economia das Instituições. Discute em quais situações os leilões surgem como uma forma eficiente de governança, a partir dos condicionantes dados pelo ambiente institucional. São enfocadas em particular as transações que ocorrem ao longo do sistema agroindustrial da carne bovina, em comparação com arranjos alternativos de governança, especialmente a venda direta no mercado spot e a venda direta por meio de outros arranjos contratuais. Dentro deste sistema se inserem as transações existentes no mercado de animais de raça, no mercado de animais de reposição e no mercado de animais terminados para abate, sendo este último o enfoque central do presente artigo. As evidências da pesquisa realizada que deu origem a este artigo apontam no sentido de que as características do ambiente institucional explicam, em muitas situações, as escolhas alternativas das instituições de governança na comercialização de animais. Prevalecem as formas mais eficientes no sentido de redução dos custos de transação. Os custos de transação são subdivididos para discussão em custos informacionais, custos de negociação e custos de monitoramento.

Palavras-chave: leilões, eficiência dos mercados, ambiente institucional, estruturas de governança, rastreabilidade. 


\section{Introdução}

耳 ste trabalho discute o papel dos leilões como Cum instituição de governança dentro do sistema de vendas de animais no Brasil, a partir do referencial teórico da Nova Economia das Instituições. Discute em quais situações os leilões surgem como uma forma eficiente de governança, a partir dos condicionantes dados pelo ambiente institucional.

São enfocadas as transações que ocorrem ao longo do sistema agroindustrial da carne bovina, em comparação com arranjos alternativos de governança, especialmente a venda direta no mercado spot e a venda direta por meio de outros arranjos contratuais. Dentro deste sistema inserem-se as transações existentes no mercado de animais de raça, no mercado de animais de reposição e no mercado de animais terminados para abate. No presente artigo, o enfoque está centrado no mercado de animais terminados para abate. A questão central está na identificação das condições em que prevalecem as distintas estruturas de governança citadas. Embora o modelo proposto possa ser utilizado para a explicação dos diversos mercados de animais e com adaptações para outros mercados, optou-se por analisar apenas o mercado de animais terminados para abate pelas maiores evidências empíricas obtidas no levantamento realizado. Os autores realizaram diversas entrevistas com agentes ligados aos setores da indústria frigorífica no Brasil e Argentina, visando obter evidências comparativas das situações nas quais os frigoríficos realizavam suas compras via leilões, via contratos ou via mercado spot. No Brasil, a prática corrente é a aquisição via mercado spot, enquanto na Argentina os leilões assumem um papel de maior destaque na comercialização de gado para abate. A pesquisa serviu como base para a elaboração da dissertação de mestrado intitulada "O Mercado de Animais no Brasil e a Evolução do Sistema de Leilões" - São Paulo, 1997.

O leilão não é um mercado puro. Trata-se de um sistema em que, a partir do papel de mediação do leiloeiro, são estabelecidas as regras do jogo para os seus participantes. No presente trabalho, os leilões serão caracterizados como um modelo de governança, visando facilitar as trocas de direitos de propriedade, no sentido de "fazer o mercado fluir mais eficientemente".

$\mathrm{Na}$ economia institucional, os mercados são supostos como podendo ser imperfeitos e caracterizados por possuírem custos de transação positivos (embora possa existir a situação polar de custo de transação igual a zero), requerendo assim instituições que regulem os direitos de propriedade e contratos, como, por exemplo, instituições e organizações de mercado. A partir deste pressuposto, TILBURG (1995:9) coloca como questão importante o desenho institucional que propicie maior eficiência na alocação de recursos:

"Relative market prices and the institutional setup. What types of institutions help to overcome market imperfections?"

No contexto deste trabalho, o questionamento de TILBURG pode ser uma das alternativas de se abordar uma outra indagação, no caso específico do papel dos leilões no mercado de animais:

"Why buyers and sellers of cattle sometimes use the auction and at other times rely on direct sales is a fascinating question" (ALLEN, 1993:481).

Para evidenciar respostas, é importante definir o que distingue o leilão de um mercado tradicional, ou ainda, o que distingue uma transação via leilão de uma transação direta.

$\mathrm{O}$ problema básico deste trabalho refere se à determinação das condições em que prevalece o arranjo de governança via leilão em relação à negociação direta no mercado de animais. É, portanto, um problema de eficiência comparada.

Esta problemática nos remete também ao papel dos leilões dentro do mercado, no sentido de fazer com que o sistema de preços funcione de maneira mais eficiente. Conforme argumentação de HAYEK (1945:525), omitir as imperfeições das informações é ignorar a maior vantagem do sistema de preços:

"The marvel of the price system is its efficiency in communicating information in a system in which the knowledge of the relevant facts is dispersed among many people". 
RUFFIN (1988) aponta que os custos de informação ocorrem porque as pessoas têm limitada capacidade para aquisição, processamento, armazenagem e resgate de informações relacionadas à alocação de recursos. Uma vez que os custos de informação são positivos, torna-se evidente que o funcionamento dos mercados tem custo. A economia neoclássica tradicional assume, implicitamente, que os agentes possuem informação completa e simétrica, desconsiderando incertezas relacionadas à própria mensuração, aos atributos de qualidades do bem transacionado, e ao comportamento dos competidores e parceiros. A Economia dos Custos de Transação (E.C.T.), ao contrário, enfoca como as transações ocorrem, e as razões para o comportamento dos agentes nas transações, sugerindo que a natureza e o nível de custos de transação determinam a forma de coordenação vertical (HOBBS, 1996).

Neste contexto, a proposta deste trabalho é focar a análise da instituição de governança via leilão, em termos de custos de transação, a partir de 3 formas: os custos de informação, os custos de negociação e os custos de monitoramento.

Em situações em que os leilões conseguem diminuir a assimetria de informações entre as partes envolvidas nas transações, sinalizar de maneira mais clara referenciais de preço e qualidade para os bens transacionados, e facilitar o encontro dos ofertantes e potenciais demandantes, eles contribuem para um melhor funcionamento do sistema de preços, no sentido de reduzir os custos de transação envolvidos. Ao contrário, em casos em que os custos de transação que emergem da comercialização via leilões forem maiores, advindos do aumento dos custos de monitoramento, negociação ou informação, esta instituição de governança não deverá prevalecer, sob a ótica da E.C.T.

\section{Os Leilões}

\subsection{Os Tipos de Leilão}

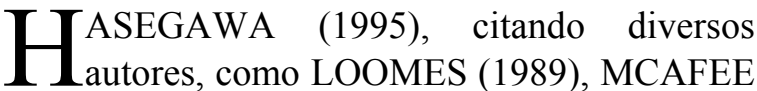

\& MCMILLAN (1987) e MILGROM \& WEBER (1982), menciona quatro tipos básicos de leilões: o leilão inglês, de lances abertos e crescentes; o leilão holandês, de lances decrescentes; o leilão de lance fechado de primeiro preço e o leilão de lance fechado de segundo preço (leilão de Vickrey).

$\mathrm{O}$ leilão inglês se caracteriza por lances sucessivos, nos quais os interessados ofertam valores crescentes, até o lance mais alto, que é o lance comprador.

O leilão do tipo holandês é o método no qual o leiloeiro estipula um preço máximo, a partir do qual um mostrador começa a apontar decréscimos de preço, até que alguém ofereça o primeiro lance, que é o lance comprador.

A diferença entre o leilão fechado de primeiro e segundo preço é que, no primeiro, cada comprador potencial faz um lance fechado, sendo vencedor o lance mais alto. No leilão fechado de segundo preço, o lance mais alto irá definir o comprador, mas o valor a ser pago é definido pelo segundo lance atribuído.

A seguir, serão apresentadas em maiores detalhes as características e alguns exemplos práticos da utilização dos leilões dos tipos holandês e inglês.

\subsubsection{O Método Holandês (Veiling)}

No método holandês, cada comprador registrado no leilão tem o seu assento próprio e são conectados com um equipamento informatizado, responsável pela recepção dos lances. Todo este processo de compra é extremamente rápido, e os produtos vão adentrando no auditório do pregão ininterruptamente.

Este sistema pode ser observado no Brasil na comercialização de flores pela Cooperativa Agrícola de Holambra, desde 1989, num sistema de vendas em leilão denominado Veiling (leilão em holandês). Por ser mais rápido e ágil, este sistema serve melhor a leilões de bens de baixo valor unitário e grande quantidade ofertada. $\mathrm{O}$ autor teve a oportunidade de visitar o leilão de flores (Veiling) da Cooperativa de Holambra em 
Jaguariúna/SP, 1993, e posteriormente, em junho de 1995, visitar o "Verenidge Bloemenveiling Aalsmeer Auction", em Aalsmeer (Holanda). Este centro de comercialização pertence a uma cooperativa de produtores de plantas ornamentais e flores. É considerado o maior centro de comercialização de plantas e também o maior edifício comercial do mundo, possuindo uma área de 715.000 metros quadrados, onde cerca de 50.000 transações comerciais são realizadas diariamente (PINHEIRO MACHADO, CHADDAD, SPERS \& NEVES, 1996). Criado em 1912, estima-se que o Veiling de Aalsmeer movimenta cerca de US\$ 2 bilhões de vendas ao ano (ROOYEN \& OPTIZ, 1997).

De acordo com ROOYEN \& OPTIZ (1997), em 1996 cerca de $40 \%$ da produção brasileira de flores foram comercializados pelo Veiling da Holambra, antes de chegar ao consumidor final. Os mesmos autores afirmam que o leilão é uma peça-chave do sistema, estimulando a competição entre os compradores na aquisição dos produtos, dando transparência ao mercado. A inexistência deste sistema levaria os produtores de flores a uma posição de negociação muito desfavorável, em função da perecibilidade do produto.

Conforme ZYLBERSZTAJN (1992), a origem destes leilões com preços decrescentes na Holanda foi em 1887. Esta iniciativa visava agilizar o processo em vigor (leilões com preços ascendentes), que se verificavam na prática muito morosos para o escoamento de grandes volumes comercializados, além do que propiciava a formação de cartéis de compradores. ZYLBERSZTAJN destaca a importância econômica deste sistema de vendas na Holanda, do qual participam cerca de 20.000 produtores (20\% do total do país). A organização destes leilões se dá pelo intermédio de Cooperativas de Produtores, que mantêm desta forma canais próprios para a venda de seus produtos.

A função básica destes leilões é propiciar um espaço físico para o encontro de oferta $\mathrm{e}$ demanda. Este processo determina o preço. O papel coordenador dos leilões é destacado como forma de controle da oferta, aumentando o poder de barganha por parte do produtor, além da garantia adicional do sistema de preços mínimos. Pelo sistema de preços mínimos utilizado nos Veilings, quando um lote cai abaixo de um limite preestabelecido, o lote é retirado da negociação e destruído publicamente, impedindo que a mercadoria seja negociada a um preço abaixo do custo (ROOYEN \& OPTIZ, 1997).

\subsubsection{O Método Inglês}

O método inglês caracteriza se pela sucessão de lances crescentes, até que se tenha apenas um lance remanescente, que é o lance vencedor. Pode ter ou não a salvaguarda do lance mínimo (reserve price), a partir do qual as ofertas se iniciam. É na prática o método mais utilizado na venda de bens por leilões, como na venda de animais. Em todo o mundo este método é utilizado na comercialização de diversas classes de animais, como bovinos, equinos, caprinos, suínos, entre outros, tanto na forma tradicional de vendas (pela interação direta do agente leiloeiro com o público, sem a possibilidade de interação à distância por sistemas eletrônicos) como pelos sistemas eletrônicos. No Brasil, também as formas tradicional e eletrônica coexistem, mas o método mais utilizado ainda é o tradicional, com ou sem preço mínimo. Em alguns casos os vendedores estipulam a salvaguarda do preço mínimo pelo animal, não havendo negociação caso não se atinja este patamar. O código de lances é variável, com uma tipologia própria, podendo ser um aceno, balanço de cabeça etc. A cada momento, todos os compradores têm conhecimento do lance predominante.

\section{O Ambiente Institucional e a Economia dos Custos de Transação (ECT)}

\subsection{Aspectos gerais}

To presente trabalho, é relevante a definição 1 que NORTH (1990) oferece para caracteri- 
zar a importância do ambiente institucional e sua relação com a performance dos agentes econômicos num determinado mercado, aplicando esta abordagem na análise da história econômica.

$\mathrm{O}$ autor define as instituições como sendo os limites que as sociedades se impõem para estruturar as relações políticas, econômicas e sociais. Assim, as instituições podem ser tanto formais (constituições, leis, direitos de propriedade) como informais (crenças, tradições, códigos de condutas e costumes).

NORTH procura estabelecer uma relação entre instituições e organizações: as instituições constituem-se nas regras do jogo e as organizações são os jogadores. "If institutions are the rules of the game, organizations and their entrepreneurs are the players" (1994:361).

Dentro desta abordagem, as limitações que são impostas pelo contexto institucional ajudam a definir o conjunto de oportunidades, e como conseqüência os tipos de organizações que serão criadas. As organizações existentes em um determinado mercado e a forma como interagem são influenciadas por um determinado ambiente institucional. Assim, uma mudança no ambiente institucional pode levar a uma mudança na forma de conduta das organizações, e mesmo no surgimento de outras.

Estas organizações também podem, por sua vez, atuar na alteração de um dado ambiente institucional, num processo de feedback, alterando um dado modelo institucional existente.

NORTH (1994) afirma que os resultados preconizados pela teoria neoclássica só são, na verdade, obtidos quando não existem custos para se transacionar, apontando, no entanto, que (texto do discurso de prêmio Nobel, publicado no periódico American Economic Review com o título "Economic Performance Through Time" (1994)):

"When it is costly to transact, then institutions matter".

Este é o pressuposto fundamental da ECT, de que o funcionamento dos mercados tem custos, em contrapartida à visão dada pela economia neoclássica, que ocorre em um ambiente sem custos associados ao funcionamento da economia. ARROW (1969:48) define custos de transação num sentido amplo como sendo "...the costs of running the economic system".

WILLIAMSON (1993), em contrapartida aos pressupostos neoclássicos, aponta para a ficção do custo de transação igual a zero. $\mathrm{Na}$ sua definição, os custos de transação são:

"Os custos ex-ante de preparar, negociar e salvaguardar um acordo bem como os custos expost dos ajustamentos e adaptações que resultam, quando a execução de um contrato é afetada por falhas, erros, omissões e alterações inesperadas. Em suma, são os custos de conduzir o sistema econômico".

Para NORTH (1994), os custos de transação são definidos como aqueles custos relativos a especificar o que está sendo comercializado e a assegurar que os conseqüentes acordos sejam cumpridos. Nos mercados econômicos, o que se especifica (mede) são os atributos valoráveis dos bens e serviços transacionados ou a performance dos agentes. $\mathrm{O}$ autor sustenta que os mercados econômicos são tipicamente imperfeitos e caracterizados por altos custos de transação.

Assim, num contexto de comportamento dos indivíduos caracterizado pela busca de maximização de riqueza e informações assimétricas acerca dos atributos do determinado bem que está sendo transacionado, os custos de transação emergem como determinantes críticos da performance econômica. Como conseqüência, as instituições, para serem efetivas, devem atuar especialmente no sentido de ressaltar as soluções cooperativas. Em termos de custos de transações, as instituições devem ter o papel de reduzir os custos de transação e produção para que os ganhos potenciais envolvidos nas transações se realizem.

\subsection{Características das Transações}

De acordo com WILLIAMSON (1985), as principais dimensões que devem ser observadas na descrição das transações são a especificidade dos ativos, incerteza e freqüência. Os ativos são 
classificados pelo autor em 3 classes: nãoespecíficos, mistos ou altamente específicos, e em termos de freqüência as transações são classificadas em recorrentes, ocasionais ou únicas.

Quanto maior a freqüência das transações, maiores as vantagens de se manter estruturas especializadas, com menores custos fixos médios. Por exemplo, a aquisição de um equipamento a ser utilizado em uma linha de produção não ocorre com freqüência e a transação é única. No entanto, a aquisição de um determinado insumo industrial que será utilizado continuamente é um tipo de transação do tipo recorrente.

A incerteza é, dos três atributos das transações considerados por WILLIAMSON, a que tem menor desenvolvimento conceitual. Conforme aponta ZYLBERSZTAJN (1995), representa um enorme campo para aprofundamento teórico. Basicamente, pode-se considerar que existam dois tipos de incerteza: a incerteza proveniente do comportamento estratégico dos agentes, isto é, a incerteza decorrente da impossibilidade de saber as ações que os agentes irão colocar em prática; e a incerteza de contingência (estado da natureza), ou seja, a incerteza inerente à própria atividade e a impossibilidade de se prever todas as possibilidades ou contingências, que ocorrerão num tempo futuro, que afetem a atividade.

A especificidade dos ativos se refere a quanto um determinado ativo é específico para a atividade, e quão custosa é a sua realocação. WILLIAMSON (1996) define basicamente seis tipos de especificidade dos ativos. Pode ser locacional (ex. grau de proximidade física), temporal (ex. perecibilidade), humana (ex. funcionários altamente qualificados), física (ex. componentes específicos de um produto), ativos dedicados (investimentos do tipo sunk costs - ativos irrecuperáveis) e de marca (brand name). À medida que a especificidade aumenta, aumentam também as implicações decorrentes de comportamentos oportunistas dos agentes, pois surgem quase-rendas associadas. $\mathrm{O}$ conceito de quaserendas é tratado por KLEIN, CRAWFORD \& ALCHIAN (1978), citados em ZYLBERSZTAJN (1995), como o excesso de valor de um ativo sobre o seu uso de oportunidade ou valor residual. Assim, conforme a especificidade se eleva, quase-rendas são criadas aumentando as possibilidades para ações oportunísticas.

A partir da análise destes atributos envolvidos nas transações, o autor identifica as formas de "governança" mais eficientes, no sentido de reduzirem os custos de transações. Segundo WILLIAMSON apud ZYLBERSZTAJN (1995:51), "a existência de uma variedade de arranjos contratuais, sob a ótica da E.C.T., advém das diferenças de atributos das transações reguladas por estes contratos".

MACNEIL (1978) define três tipos de contratos: clássicos, neoclássicos e relacionais. Os contratos clássicos ocorrem quando existem transações isoladas, sem efeito intertemporal (isto é, ocorrem no período $t$ independentemente do que ocorreu no período $\mathrm{t}-\mathrm{n}$ ou ocorrerá no período $\mathrm{t}+\mathrm{n}$ ), discretas, descontínuas, com regras claras, em que os possíveis ajustes se dão via mercado. Este tipo de contrato está relacionado ao conceito da economia neoclássica de competição perfeita. Neste sentido, ao não se poder definir ex-ante todos os termos contratuais, o arranjo clássico é muito limitado.

Os contratos neoclássicos ocorrem para transações em que existe continuidade e adaptação, estando implícita a existência da racionalidade limitada e da incerteza. Neste tipo de contrato, podem ocorrer arranjos. Como cita ZYLBERSZTAJN (1995:54), “a sociedade criou diferentes maneiras para fazer face às necessidades de contratos de longo prazo para efetivar a atividade produtiva... exemplos destes arranjos podem ser encontrados na definição de padrões de ampla aceitabilidade, na aceitação de assistência de terceiros para a solução de disputas e nas diferentes formas pelas quais as partes demonstram, entre si, que desejam manter a continuidade do contrato, cuja terminação traria custos para ambas as partes, custos estes superiores aos custos de negociação".

Já no contrato relacional, a flexibilidade é uma característica básica, com a possibilidade da renegociação, podendo o contrato original deixar 
de ser a base para esta nova negociação. É baseado fortemente no conceito da incompletude dos contratos dado o pressuposto da racionalidade limitada. MACNEIL (op. cit.) salienta que, num contrato relacional, o ponto de referência é a relação negocial como um todo. Segundo ZYLBERSZTAJN (1995:56), parte da literatura acerca de alianças estratégicas, negociações trabalhistas, contratos entre clientes e fornecedores, entre outros arranjos, está fortemente centrada neste tipo de comportamento relacional, trocando-se o esforço do desenho de um contrato completo, pelo esforço de um sistema negocial continuado, em função das variáveis ambientais.

De acordo com WILLIAMSON (1985), em função dos atributos presentes nas transações, as formas de governança resultantes se dão via mercado, formas mistas ou via hierárquica (firma), refletindo uma ação otimizadora (minimizadora de custos de transação mais custos de produção). Em casos de ativos com baixa especificidade, a forma mais eficiente de governança se dá na transação via mercado. No outro extremo, para ativos altamente específicos, a transação com menores custos de transação se dá na forma integrada. As relações entre os tipos de contratos e as formas de governança resultantes estão, de acordo com WILLIAMSON (1985), em função da freqüência (ocasional ou recorrente) e do grau de especificidade. A incerteza neste caso está intrínseca, dado que as adaptações decorrem exatamente da impossibilidade de se enumerar todas as futuras contingências.

A forma organizacional via mercado se dá pelo sistema de preços. A forma hierárquica se dá pela internalização dos segmentos a montante ou a jusante, e a forma híbrida envolve uma série de contratos complexos, como alianças estratégicas, joint ventures, licenciamentos, franquias etc.

As formas organizacionais via mercado têm maior congruência com contratos do tipo clássico, as formas híbridas com contratos neoclássicos ou relacionais e as formas hierárquicas com contratos do tipo relacional.

A Figura 1 ilustra a relação entre os custos das diferentes estruturas de governança e nível de especificidade dos ativos (k). As curvas $\mathrm{m}, \mathrm{x}$, $\mathrm{e} h$ representam respectivamente as formas mercado, mista e hierárquica. Na medida em que $\mathrm{k}$ aumenta, as relações de menores custos passam da forma mercado (até ponto A) para forma mista (intervalo A-B) e hierárquica (após o ponto B).

No presente trabalho, as características das transações serão utilizadas para a análise da maneira mais eficiente de governança. $\mathrm{Na}$ comercialização de animais, duas das formas de governança a serem consideradas no presente estudo estão dentro da alternativa via mercado, embora no sentido puro strictu sensu do mercado - laissez-faire -, apenas a venda direta (do tipo mercado spot, contrato clássico) possa ser considerada mercado, uma vez que, no caso do leilão, esta instituição de governança age como catalisadora do encontro de oferta e demanda, atuando como uma mão visivel (portanto não mais mercado na forma estrita) no processo de troca de direito de propriedade. Neste caso, a relação que emerge em um leilão poderia ser considerada um tipo de contrato neoclássico, com dependência trilateral, ou seja, das partes envolvidas e da intermediação do processo.

A outra alternativa de governança a ser considerada é a venda direta por relações contratuais do tipo mista, quer sejam contratos neoclássicos ou relacionais. Neste caso, a venda direta se dá por algum tipo de acordo, formal ou informal, como contratos de fornecimento, alianças estratégicas, parcerias etc., ou, no limite, a forma hierárquica, que já seria a última alternativa de governança.

Deseja-se saber, neste estudo, qual das instituições de governança (leilões ou venda direta) prevalece, para os mercados em análise, no sentido de propiciar economias em custos de transação. Conforme exposto por ARNOLD \& LIPPMAN (op. cit.), analisando diferentes instituições de venda no mercado de animais norte-americano:

"Although economists have devoted considerable attention to the optimal design of each of these institutions, they have paid relatively little 
C.T

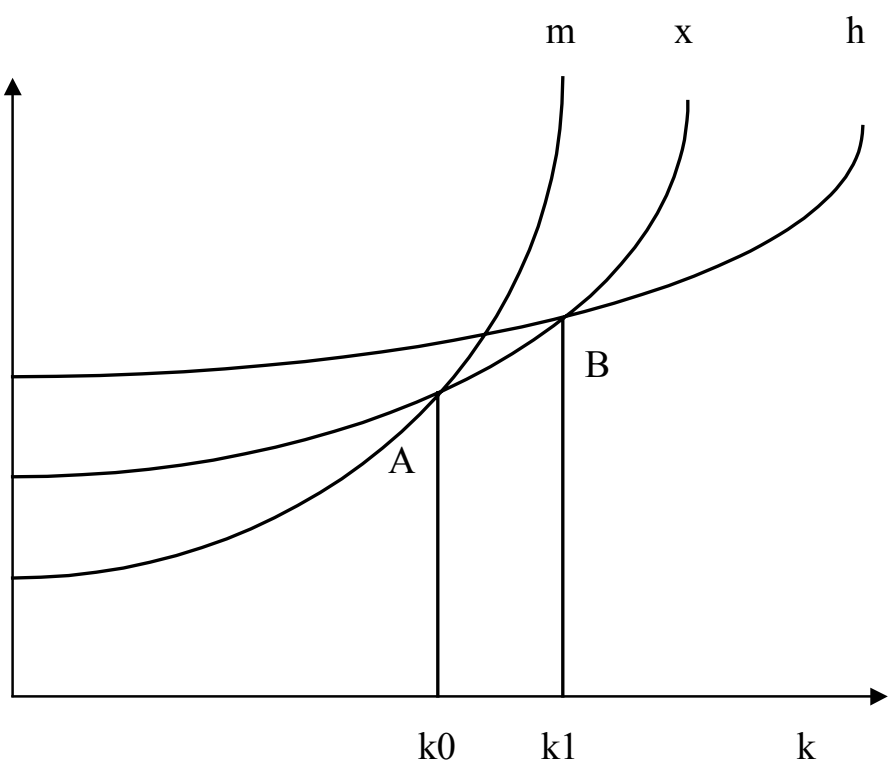

Figura 1 - Relação entre estruturas de governança e especificidade de ativos. Fonte: WILLIAMSON (1985).

attention to explain the simultaneous existence of these different institutions or the factors which govern the sellers's choice of a specific selling institution".

\subsection{Um modelo com base no atributo das transações}

Neste tópico, a partir das descrições anteriores, relacionando aspectos dos leilões de animais e os atributos das transações, será apresentado um modelo que relaciona a especificidade dos ativos e o aumento nos custos de transação, comparando-se a alternativa de governança via leilões e a venda direta (negociação direta, no mercado spot, ou via algum tipo de relação contratual mista).

A transação via leilão pode ter diversas características em função da própria natureza dos bens em questão que estarão sendo transferidos. A análise dos leilões enquanto estrutura de governança será centrada em um modelo simplificado, restrito especificamente ao mercado de gado.

$\mathrm{O}$ modelo proposto a seguir será tentativamente explicativo em relação às formas alternativas de governança via leilão do tipo inglês e à negociação direta, seja via mercado puro (spot) ou via contratual mista. Utilizando-se do aparato proposto por WILLIAMSON (1985), os atributos relevantes das transações são a especificidade dos ativos, freqüência e incerteza.

$\mathrm{O}$ atributo da incerteza, tem a sua relevância quanto ao aspecto contingencial (estado da natureza), inerente à atividade, com a impossibilidade de prever as contingências que poderão ocorrer no futuro. Este atributo está presente em maior ou menor grau nas transações. A venda de ações de uma determinada empresa, a venda de direitos de exploração, a venda de um bezerro, todos são exemplos que acarretam forte grau de incerteza quanto aos retornos potenciais esperados destas aquisições. Conforme apontam MILGROM \& WEBER (1992), os leilões têm tradicionalmente um papel de destaque na venda destes tipos de bens, que pelas suas características têm sua valoração exposta a um alto grau de subjetividade.

No mercado de animais, existe a incerteza contingencial, inerente à própria atividade. Assim, a aquisição de um reprodutor, uma 
matriz de raça, ou animais jovens (novilhos, bezerros, potros etc.) trazem um elevado grau de incerteza relacionado à sua performance dentro das suas aptidões. Esta incerteza poderá estar presente com ou sem a ocorrência de assimetria informacional.

Como exemplo de ocorrência de assimetria informacional, que poderia potencialmente gerar um tipo de comportamento oportunista, seria o caso da venda de uma matriz, numa situação em que o vendedor tenha conhecimento de atributos negativos do animal, informação esta não disponível ao comprador. A incerteza sem a assimetria informacional pode ser ilustrada pelo exemplo de um animal jovem que ainda não teve sua performance reprodutiva testada (neste caso, existe a ausência da informação tanto para o vendedor como para o comprador).

Em países onde ocorre a compra de gado pelos frigoríficos via leilões, esta compra pode estar associada a um certo grau de incerteza, também sem assimetria informacional. No leilão, o comprador estará comprando o animal com base no seu "peso vivo". Assim, existe o risco de que o comprador pague um preço com base na expectativa do rendimento da carcaça do animal após abatido ("peso morto"), que pode não se verificar efetivamente.

A freqüência é um outro atributo presente nas transações importante de ser destacado pelas suas implicações nas vendas efetuadas em leilões. Em determinados mercados, nos quais os compradores e vendedores interagem recursivamente, em períodos de tempo definidos (como por exemplo, em leilões em que são comercializados animais ou produtos vegetais produzidos ciclicamente), cria-se um ambiente menos propício a comportamentos oportunistas, tanto de parte dos compradores como vendedores, sob pena de perda de reputação. O "papel da reputação", neste caso, assume grande importância. Conforme apontam MILGROM \& ROBERTS (1992:139):

"... the concern with getting a bad reputation that reduces future possibilities for profitable transactions can limit reneging. Effectively, it removes the incentives for opportunistic behaviour by creating a cost offsetting the shortterm gains of opportunistic behaviour".

Num mercado de animais no qual os agentes interagem recursivamente, o ambiente institucional (via coerção do grupo) atua no sentido de redução dos custos de transação associados a comportamentos oportunistas dos agentes. Desta forma, pelo fato de que nestes mercados o ciclo de vendas de cada criador tende a se repetir a cada temporada, o aspecto da recursividade assume importância, pois o público-alvo em cada ocasião será basicamente o mesmo, existindo, além disso, grande intercâmbio de informações entre os criadores, sendo fator inibidor de comportamentos oportunistas, tanto do lado do vendedor como do comprador (inadimplência).

O mesmo se dá nos veilings, nos quais compradores e vendedores de flores são previamente cadastrados na organização responsável pelos leilões, e atuam praticamente todos os dias na compra e venda dos produtos.

Quanto à especificidade dos ativos comercializados, no Brasil, embora exista no caso dos animais de reposição (gado geral) uma certa variabilidade entre os lotes ofertados, basicamente as únicas variáveis que os diferenciam se relacionam com questões do porte físico, sexo e idade do animal. Ainda não existem sistemas de classificação e tipificação de carcaças. Embora a especificidade do produto no caso dos animais de reposição não seja relevante, a especificidade locacional pode ser elevada.

Para o caso dos animais de raça, existe um série de atributos do produto, como a genealogia, origem criatória, idade, aspecto visual, premiações obtidas, características morfológicas etc. Por exemplo, certas diferenças fenotípicas mínimas observadas entre um animal e outro podem levar a uma enorme variação de preços. Nestes casos, a marca do criador (brand name) assume significativa importância, como uma griffe dentro do meio criatório. Assim, os animais de raça se aproximam mais de um bem diferenciado, enquanto os animais de reposição possuem características de commodities. 
No caso dos animais terminados para abate, existem ainda no Brasil baixíssimas especificidades associadas ao produto, e basicamente a variável relevante é o sexo do animal (que influi no preço a ser pago pela arroba), o peso do animal vivo e seu rendimento de carcaça. Nenhum atributo da carcaça (ex. conformação e teor de gordura) é valorado.

Embora as variáveis de incerteza e freqüência sejam altamente relevantes, no modelo proposto a variável relacionada com a especificidade do ativo negociado será o atributo único a ser considerado. Assume-se que a instituição de governança preferível (leilão ou negociação direta), em termos de redução de custos de transação, irá variar em função da especificidade dos ativos (produto). Serão consideradas três curvas de custos de transação. A curva (L) será representativa da alternativa de governança via leilão. A curva (M) representará a alternativa de governança via mercado puro (spot) via negociação direta (o mercado puro estará sendo considerado como a negociação direta, sem a intermediação do leilão). A terceira curva $(\mathrm{X})$ será representativa também de um tipo de negociação direta, embora pela via contratual mista. $\mathrm{O}$ nível $\mathrm{k}$ de especificidade estará variando de 0 até 1 (Figura 2).

Será considerado no modelo a premissa de que as transações sejam recorrentes, aplicandose especificamente aos leilões de lances abertos (leilões tipo inglês), para os animais terminados para abate (gado geral). Para simplificação do modelo, a venda direta será considerada aquela em que não ocorre uma instituição formal mediadora. Assim, mesmo nos casos das transações em que exista, por exemplo, um processo de corretagem, como a figura tradicional de "compradores" de gado, que são na realidade intermediários, este processo será considerado venda direta, pois não existe um processo "formal" estruturado de comercialização intermediando a transação.

A Figura 2 ilustra a relação entre os custos das diferentes estruturas de governança e nível de especificidade dos ativos (k). As curvas M, L e $\mathrm{X}$ representam respectivamente as formas venda direta (spot), leilões e venda direta (mista). À medida que k aumenta, as relações de menores custos passam da forma mercado spot (até ponto A) para leilões (intervalo A-B) e contratos (após o ponto B).

Ocorrendo um aumento de especificidade (associada aos atributos dos animais), supõe-se que a venda direta na propriedade (via mercado puro) seja dificultada em função da elevação do custo associado à procura dos animais (custo de negociação). Neste caso, os leilões surgiriam como uma forma redutora de custos, facilitando a realização da transação.

Do lado da oferta, para um nível maior de especificidade, haveria para o vendedor vantagens na venda em leilões comparativamente às vendas na propriedade, pois a espera até que todas as vendas ocorressem na propriedade seria muito alta. Por exemplo, numa situação em que o produtor tenha diversas categorias de animais à venda para abate, desde garrotes, vacas, novilhos, de diversos padrões, ele teria maiores dificuldades de efetuar em uma só negociação a venda de todos os animais para um determinado comprador, pois este estaria selecionando somente aqueles de seu interesse. Neste nível, os custos de transação associados aos leilões serão menores que os custos de transação via negociação direta.

Além do custo de negociação, à medida que se tenha aumentos nas especificidades, a dificuldade de mensuração se eleva, uma vez que passam a existir variações de qualidade. Quando produtos exibem qualidades diferentes, eles são separados em categorias diferentes, servindo segmentos distintos. Nestes casos, o leilão atua como redutor dos custos de obtenção da informação, podendo servir como referencial de preços eficiente.

Entretanto, existe um outro custo de transação que varia com o aumento da especificidade: o custo de monitoramento. Se, por um lado, uma instituição que transmita maior credibilidade na transferência de bens tenda a reduzir este custo, existe um outro aspecto crescentemente importante relacionado ao aumento da especificidade, 


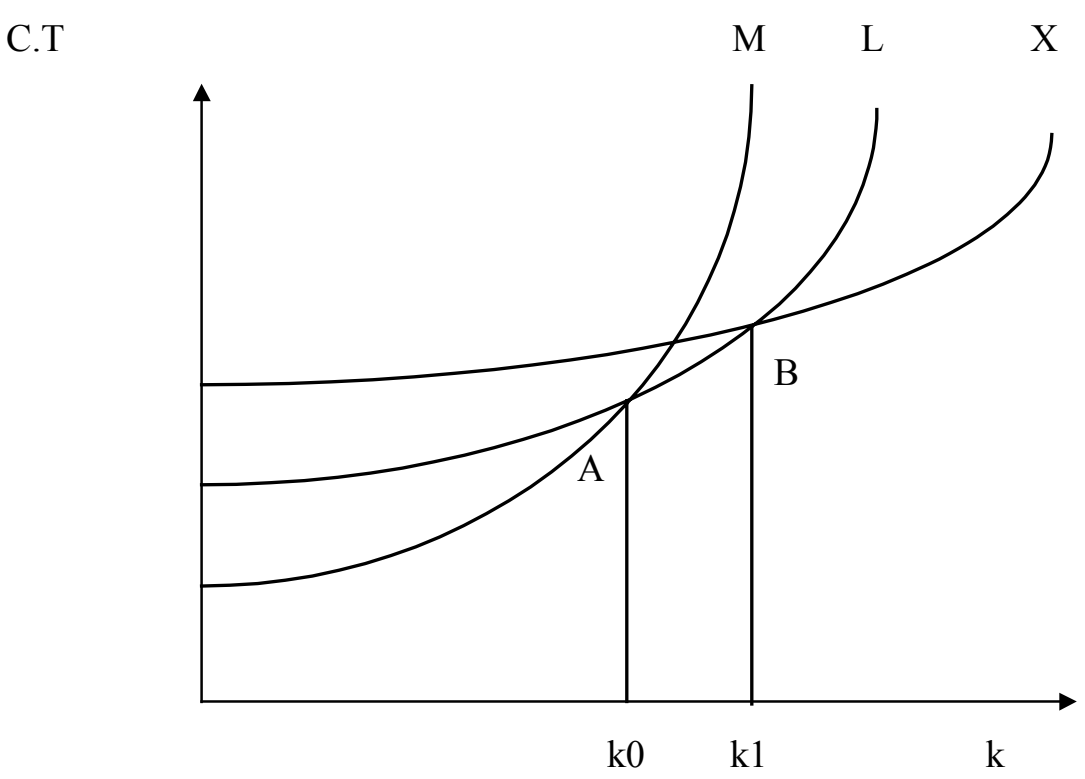

Figura 2 - Relação entre alternativas de governança (Leilão X Venda Direta).

notadamente no sistema agroindustrial da carne bovina, ligado, por exemplo, ao aumento das exigências legais e de consumo associadas à necessidade de se traçar a origem do produto final "carne". Tal custo de monitoramento associado ao rastreamento (traceability) se torna mais elevado na opção leilão, uma vez que na comercialização direta existem maiores condições para o frigorífico "rastrear" de forma mais eficiente todo o processo produtivo do animal, desde a sua origem.

Conforme aponta ZYLBERSZTAJN (1995: 170), "os atributos relacionados a segurança alimentar, resíduos e sustentabilidade dos sistemas produtivos são crescentemente incorporados às informações relevantes para o processo de tomada de decisões do consumidor de alimentos, especialmente os de maior renda, associada a melhores niveis educacionais... Em muitos países, a legislação vem alocando responsabilidades especificas para o varejista resultantes de efeitos indesejáveis dos alimentos. Assim, o varejista vem buscando informar ao consumidor de atributos específicos detalhados, de modo a criar salvaguardas no contrato implícito que uma venda significa. Tais informações devem ser supridas pela indústria, que muitas vezes deverá buscá-las junto ao produto agrícola".

Assim, o aumento da especificidade do produto final (carne) levaria a um aumento maior na especificidade da matéria-prima (boi). Nesta situação, a opção mais adequada passa a ser a venda direta, mas não na forma de mercado spot, e sim por relações contratuais, ou até mesmo, no limite, a integração vertical para trás (os frigoríficos passando a produzir) ou para frente (produtores individualmente ou em associações, verticalizando as atividades a jusante).

Assim, para $\mathrm{k}=0$ tem-se que $\mathrm{M}(0)<\mathrm{L}(0)<$ $\mathrm{X}(0)$. À medida que $\mathrm{k}$ aumenta, $(\mathrm{k}>0)$, e a partir de um determinado nível de especificidade variando no intervalo $\mathrm{A}-\mathrm{B}$, tem-se que $\mathrm{L}(\mathrm{k})<$ $\mathrm{X}(\mathrm{k})<\mathrm{M}(\mathrm{k})$, podendo ainda ocorrer a possibilidade de $\mathrm{L}(\mathrm{k})<\mathrm{M}(\mathrm{k})<\mathrm{X}(\mathrm{k})$. A partir de um nível de especificidade maior, após o ponto $\mathrm{B}$, tem-se que $\mathrm{X}(\mathrm{k})<\mathrm{L}(\mathrm{k})<\mathrm{M}(\mathrm{k})$.

A curva $\mathrm{L}$ poderá também sofrer deslocamentos, para cima ou para baixo, em função do ambiente institucional. Em situações em que a instituição de governança leilões adquire um grau de confiabilidade significativo, com padrões definidos dos produtos comercializados, e pelo grau de reputação da figura intermediária do 
leiloeiro, dentro de um ambiente formal e informal favorável, o deslocamento da curva L deverá ocorrer para baixo. Neste caso, os leilões prevaleceriam num intervalo maior de especificidade.

Já nas situações em que o ambiente institucional não é favorável, o deslocamento ocorrerá para cima (L"). No limite, em nenhum intervalo esta curva prevaleceria como a alternativa de menor custo de transação.

\section{Considerações Finais}

$\mathrm{F}$ oram enfocadas as transações que ocorrem ao longo do sistema agroindustrial da carne bovina, comparando-se a eficiência das transações via leilões em comparação com arranjos alternativos de governança, especialmente a venda direta no mercado spot e a venda direta por outros arranjos contratuais. Dentro deste sistema se inserem as transações existentes no mercado de animais de raça, no mercado de animais de reposição e no mercado de animais terminados para abate.

As evidências da pesquisa realizada apontam no sentido de que as características do ambiente institucional explicam, em muitas situações, as escolhas alternativas das instituições de governança na comercialização de animais. Prevalecem as formas mais eficientes no sentido de redução dos custos de transação. Os custos de transação são subdivididos para discussão em custos informacionais, custos de negociação e custos de monitoramento.

\section{Referências Bibliográficas}

ALLEN, D.W.: "Pot Bellies, Cattle Breeds and Revealing Signals". Economic Enquiry, vol.31, July, pp.481-487, 1993.

ARNOLD, M.A. \& LIPPMAN, S.A.: "Selecting a Selling Institution:Auctions versus Sequential Search". Economic Enquiry, vol.33, p.1-23, Janeiro, 1995.

BAILEY, D.V. \& BRORSEN, B.W.: "Dynamics of Regional Fed Cattle Prices". Western Jornal of Agricultural Economics, 10(1), p.126-133, jul 1985.

BUCCOLA, S.T.: "Pricing Efficiency in Centralized and Noncentralized Markets". American Journal of Agricultural Economics, 67(3), p.583-590, aug 1985.

BULOW, J. \& KLEMPERER P.: "Auctions X Negotiations". American Economic Review, vol.86, p.180-194, mar 86.

COASE, R.H.: "The Problem of Social Cost". The Journal of Law and Economics n.3 In: NORTH, D.C. Custos de Transação, Instituições e Desempenho Econômico. Instituto Liberal, Rio de Janeiro, 1994.

HASEGAWA, M.M.: O mercado de reposição de animais da pecuária de corte no estado de São Paulo. Dissertação de Mestrado, ESALQ/USP Piracicaba/SP, mimeo, 1995.
HAYEK, F.A.: "The Use of Knowledge in Society". American Economic Review, 35(4), p.519-530, Sept., 1945.

HOBBS, J.E.: "Transaction Costs and Slaughter Cattle Procurement: Processors' Selection of Supply Channels". Agribusiness, v.12, n.6, p.509-523, Nov./Dec, 1996.

LOOMES, G.: "Experimental Economics" In: HEY, J.D. Current Issues in Microeconomics. Hampshire: Mc Millan, 1989.

MACNEIL, I.: “Contracts: adjustments of long-term economic relations under classical, neoclassical and relational contract law". Nortwestern University Law Review, 72p., 1978.

McFEE, R.P. \& McMILLAN, J.: "Auctions and Bidding”. Journal of Economic Literature, 25(2), jun 1987.

MILGROM, P.R. \& WEBER, R.J.: "A Theory of Auctions and Competitive Bidding”. Econométrica, 50(5) sep, 1992.

MILGROM, P. \& ROBERTS, J.: Economics, Organization and Management, Prentice-Hall International Inc., 621p., 1992.

NABLY, M.K. \& NUGENT, J.B.: "The New Institutional Economics and its Applicability to Development". World Development 17, 9, p.1333-1347, 1989. 
NORTH, D.C.: "Institutions, Institutional Change and Economic Performance". Cambridge University Press, 1990.

NORTH, D.C.: Custos de Transação, Instituições e Desempenho Econômico. Instituto Liberal, São Paulo, 38p., 1994.

PINHEIRO MACHADO, C.A.: "Leilões de Animais no Brasil". Revista de Administração, USP, São Paulo, 29(1):76-82, jan/mar. 1994.

PINHEIRO MACHADO, C.A.; CHADDAD, F.; SPERS, E. \& NEVES, M.: Agribusiness Europeu. Editora Pioneira, p.40-42, 1996.

PINHEIRO MACHADO, C.A.: O Mercado de Animais no Brasil e a Evolução do Sistema de Leilões. Dissertação de mestrado apresentada na Faculdade de Economia, Administração e Contabilidade da Universidade de São Paulo, 1997.

ROOYEN S. \& OPTIZ R.: “Veiling - Leilão Eletrônico de Flores da Holambra". Revista Preços Agrícolas, p.24-26, n.127, 1997.

TILBURG, A.: "Framework to Assess the Performance of Food Commodity Marketing Systems in Developing Countries". Trabalho apresentado em conferência do Reseau SADAOC - "Sustainable Food Security in West Africa" Gana, 15p., mimeo, março de 1995.
THOMSEN, F.L.: Agricultural Marketing. Mc Graw Hill, p.109, 1951.

WILLIAMSON, O.E.: The Economic Institutions of Capitalism: Firms, Markets, Relational Contracting. New York: The Free Press, 450p., 1985.

WILLIAMSON, O.E.: "Transaction Cost Economics and Organizational Theory". Journal of Industrial and Corporate Change, 2, p.107-156.985, 1993.

WILLIAMSON, O.E.: "The Mechanisms of Governance". Oxford University Press, New York, 429p., 1996.

ZYLBERSZTAJN, D. et al.: "Holanda: Um Modelo de Agribusiness". Estudo temático apresentado no II Seminário Internacional PENSA de Agribusiness. PENSA/FIA/FEA/USP. 90p. (mimeo), São Paulo, 09/92.

ZYLBERSZTAJN, D.: Estruturas de Governança e Coordenação do Agribusiness: Uma aplicação da Nova Economia das Instituições. Tese de Livre Docência apresentada ao Departamento de Economia, Administração e Contabilidade/USP. São Paulo, p.238, 1995.

\title{
THE AUCTIONS - AN APPROACH BASED ON THE NEW INSTITUTIONAL ECONOMICS THEORY
}

\begin{abstract}
This paper discusses the role of auctions as a governing factor in the livestock market in Brazil (especially cattle), considering the framework of the transaction costs economics. The main question is to discuss under which situations the auctions emerge as an efficient governing structure, compared with other forms of governance, whether contractual forms or the spot market. The paper compares some alternative arrangements, such as direct sales or contractual relationship, along the beef chain, from the farmer to slaughterhouses and among farmers. The costs of negotiation, information and monitoring that emerge in different institutional environments are the key aspects that explain the conditions in which auctions prevail or not as a superior governance structure in the livestock market.
\end{abstract}

Key words: governing structure, livestock market, auctions, efficiency. 